\title{
OS CRITÉRIOS OPERATIVOS DA BOA FÉ NO ÂMBITO DAS CLÁUSULAS CONTRATUAIS GERAIS"
}

Cátia Sofia Marques Cebola

\section{SUMÁRIO}

\section{Introdução}

1. O princípio da liberdade contratual e o fenómeno das CCG: a morte anunciada de um princípio ou a sua contínua revivescência

2. Caracterização geral da categoria contratual em discussão

3. A boa fé como critério de validade das $C C G$

3.1. O sistema de controlo de conteúdo das CCG: o método inerente ao catálogo de proibições

3.2. Boa fé, bons costumes e ordem pública

3.3. Critérios operativos da boa fé

3.3.1. Análise do artigo $16^{\circ}$ do $D L n^{\circ} 446 / 85$

3.3.2. $O$ art. $3^{\circ}$ da Directiva sobre cláusulas abusivas

Conclusão

\section{INTRODUÇÃ̃O}

As sociedades contemporâneas assistem a alterações sociais, económicas e comerciais significativas que exigem dos seus agentes a criação de instrumentos práticos adequados à realização dos objectivos ambicionados. Tais instrumentos emergem não apenas no plano económico mas, principalmente, no domínio jurídico.

\footnotetext{
"Relatório de Mestrado realizado na disciplina de Direito Civil $I V$, no âmbito do Curso de Mestrado em Jurídico-Civilísticas, sob a coordenação do Senhor Prof. Doutor Sousa Ribeiro - Julho de 2006.
} 
$\mathrm{Na}$ verdade, assiste-se hodiernamente ao surgimento de figuras jurídicas que, não obstante a tipicidade social que evidenciam pela sua utilização reiterada, não almejam ganhar tipicidade jurídica, sendo patente a ausência de resposta normativa às mesmas.

Noutros casos, a regulamentação prescritiva destas realidades apresenta-se a posteriori, reclamada por razões de certeza, segurança e harmonização jurídicas. Exemplo paradigmático desta situação encontramo-lo na figura contratual das CCG. De facto, constituindo estas uma evidência intransponível nas modernas relações contratuais, tornou-se incontornável dar resposta jurídica aos problemas que se suscitam neste âmbito. Tal resposta surge em 1985 através do DL $\mathrm{n}^{\circ}$ 446/85, de 25 de Outubro.

A intervenção legislativa torna-se tão mais premente, quando se constata que esta figura contende directamente com um dos alicerces fundamentais do Direito Civil, scilicet, a liberdade contratual. Desta relação daremos conta no início do nosso trabalho.

Face às valências dogmáticas e doutrinárias que o fenómeno das CCG convoca, restringimos o presente estudo à análise da boa fé como critério de controlo do conteúdo daquelas. Concretamente, interessa-nos abordar as diferenças normativas entre a regulamentação legal nacional deste fenómeno e dispositivo europeu sobre a mesma matéria.

A objectiva da nossa análise focará atenções, não tanto na longa lista de cláusulas abusivas previstas nos normativos legais, mas no critério de determinação do carácter abusivo quando uma determinada estipulação contratual não lograr integrar tal rol.

De facto, quer a doutrina, quer a jurisprudência têm apresentado desenvolvimentos assinaláveis no âmbito das CCG. Todavia, numa análise jurisprudencial mais atenta, percebemos que o critério geral da boa fé, a "espinha dorsal" do diploma que regula esta matéria, plasmado no art. $15^{\circ}$ do supra citado diploma, nem sempre é convocado na aferição da validade de uma cláusula concreta, assumindo um papel secundário na fundamentação dos acórdãos dos nossos tribunais.

Nestes termos, este modesto estudo pretende encetar esforços na correcta compreensão dos arrimos concretizadores do princípio da boa fé previstos nos normativos que regulam a matéria em análise. 


\section{O princípio da Liberdade Contratual e o fenómeno das CCG: a morte anunciada de um princípio ou a sua contínua revives- cência?}

O princípio da liberdade contratual, postulado fundamental da autonomia privada, constitui uma das traves mestras da «sociedade de direito privado» ${ }^{i}$ em que nos inserimos, correspondendo ao "espaço de liberdade em que as pessoas comuns podem reger os seus interesses entre si, como entenderem, através de negócios jurídicos ou de contratos, sem terem de se sujeitar a directivas de terceiros" ?.

O contrato apresenta-se, assim, como o reflexo natural do supra referido princípio. No entanto, o conteúdo do mesmo não se reduz à possibilidade de contratar (ou não contratar), tendo ínsitas também a liberdade de escolha do contraente e a liberdade de estipulação do conteúdo do acordo visado.

Ultrapassados os dogmas liberais, assentes na máxima "smithiana" laissez-faire, laissez-passer, foram sendo erigidos ao princípio da liberdade contratual vários limites cerceadores da vontade das partes e geradores da denominada crise do contrato.

As hodiernas sociedades de consumo, e as inerentes produção em série e venda em massa, contribuíram para a estandardização das relações contratuais, constituindo as CCG a face mais visível e significativa desta realidade.

Na verdade, reflectindo estas um modelo contratual no qual o elemento volitivo de uma das partes aparece subjugado a aceitar um clausulado pré-estabelecido, cujo conteúdo não foi capaz de influenciar, transfigura-se o tradicional desenho da formação do contrato e a igualdade e justiça contratuais que lhe eram subjacentes passam a ser consideradas realidades perdidas neste novo jogo de conformação de interesses.

Não obstante, entendemos que o declínio da liberdade contratual é uma previsão pessimista daqueles que não entendem a maleabilidade de

Cfr. CANaris, Claus-Wilhelm, "A liberdade e justiça contratual na sociedade jurídicoprivada", in: Contratos: actualidade e evolução, Porto, 1991, pp. 58-66.

zPEDRo Pais DE VAsconcelos, apud DRAY, Guilherme Machado, "Breves notas sobre o ideal de justiça contratual e a tutela do contraente mais débil", in: Estudos em Homenagem ao Prof. Doutor Inocêncio Galvão Telles, Vol. I, Coimbra, Almedina, 2002, p.78. 
um princípio capaz de se adaptar aos novos quadros sociais, económicos e jurídicos em que actua.

Se é inegável que a actual sociedade, regida pela globalização e celeridade das relações contratuais, exigiu modificações ao esquema contratual classicamente definido, tal não representa, porém, a morte anunciada daquele que continua, e continuará a ser, um princípio basilar da nossa ordem jurídica. Verifica-se apenas que, como nos diz ANTÓNIO ALMEIDA, "o postulado da autonomia privada e o contrato passaram a ser observados sob outra perspectiva, enquadrada num modelo de sociedade radicalmente diferente daquela que constitui a sua «ocasio legis»":.

O princípio da liberdade contratual tem assumido diferentes contornos consoante a época histórica e o fundamento subjacente à sociedade em que se concretiza. Porém, ele continua a constituir a trave mestra do Direito dos Contratos justificando, consequentemente, determinadas posições legislativas e doutrinárias.

Paralelamente à alteração da realidade que subjaz às modernas relações contratuais, assiste-se a uma redefinição do papel do Estado que, de mero espectador, passa a assumir uma intervenção social crucial que acaba, inevitavelmente, por se estender ao domínio jurídico. A intervenção legislativa é reclamada para repor a igualdade e justiça, corolários imprescindíveis do contrato.

A intervenção limitativa do poder legislativo não pode, todavia, ultrapassar os limites do necessário para repor um pressuposto capital do princípio da liberdade contratual, rectius, a negociação. É imperioso deixar às partes e ao próprio mercado margem de actuação do seu arbítrio, não devendo almejar-se uma substituição da vontade negocial que cerceie, para além do razoável, o poder jurisgénico dos sujeitos ${ }^{4}$.

Cfr. ANTónio Almeida, "Cláusulas contratuais gerais e o postulado da liberdade contratual", in: Lusíada: Revista de Ciência e Cultura, Série de Direito, Coimbra, n², 1998, p. 289.

${ }^{4}$ Acompanhamos CANARIS considerando-se que "a sociedade de direito privado" não é característica nem da sociedade feudal alicerçada em privilégios de classe, nem das sociedades comunistas nas quais o agir humano é subjugado aos objectivos da colectividade, não havendo lugar para individualismos. Cfr. CANARIS, Claus-Wilhelm, "A liberdade e justiça contratual...", cit., p. 52. 
O objectivo que deve nortear os Estados neste novo século será o de manter um equilíbrio que evite os extremos, quer do liberalismo oitocentista, quer do intervencionismo extremado que alguns países comunistas conheceram no século passado.

$\mathrm{Na}$ verdade, se não se deve expurgar a intervenção estatal dos domínios económico, social e jurídico, sempre a mesma deverá conterse dentro de certos limites, ou melhor, deverá ter como móbil garantir a liberdade de actuação dos sujeitos, limitando-se a proibir os comportamentos que em última instância anulem essa mesma liberdade ${ }^{5}$.

O regime das CCG não constitui o anúncio do óbito deste princípio que agora nos ocupa, mas antes procura a sua realização, sendo que, sem a intervenção legislativa, os pressupostos da liberdade contratual estariam irremediavelmente colocados em causa ${ }^{6}$.

No fundo, o que importa é atingir os mesmos fins (justiça contratual - suum cuique tribuere), através dos mesmos meios (autonomia contratual), apenas coadjuvados por certos arrimos (boa fé), que não desvirtuam o âmago do princípio da liberdade contratual, antes concorrem para o realizar plenamente.

O problema nevrálgico do fenómeno das CCG não reside na tutela do contraente mais frágil, pois que até o consumidor mais informado se vê confrontado com a limitação da sua liberdade contratual, maxime liberdade de conformação do conteúdo dos contratos. As especificidades deste modo de contratar, em que o sujeito se limita a aderir às cláusulas previamente fixadas e, em relação ao conteúdo das quais, não teve

\footnotetext{
${ }^{5}$ A intervenção estatal deve pautar-se pelo objectivo de garantir a liberdade e autodeterminação dos cidadãos. Esse é o objectivo das recentemente criadas e reestruturadas entidades reguladoras do mercado como a Autoridade da Concorrência, cujo finalidade não é coarctar a liberdade económica, mas apenas os comportamentos que tiverem ínsitos em si próprios um objectivo cerceador da livre concorrência. A mesma filosofia está subjacente, ou deveria estar, nos crescentes desenvolvimentos normativos no âmbito do Direito do Consumo. Em última análise, o que se pretende com a protecção legislativa dos consumidores é incrementar a confiança no mercado.

"Acompanhamos JuAN CASTRILlo SANTOS quando defende que, ao contrário da lei que é rígida e invariável, o princípio da autonomia contratual é eterno dadas as suas raízes profundas na natureza do homem como ser racional e social. Cfr. CASTRILlo SANTOS, Juan, "Autonomía y heteronomía de la voluntad en los contratos", in: Anuario de derecho civil, Madrid, tomo2, n², (Abril-Junio1949), p. 604.
} 
possibilidade de influenciar, é que constituem a guilhotina daquela liberdade .

Nesta perspectiva, a intervenção jurídica naquela que é uma incontornável realidade das actuais sociedades, scilicet, as CCG, terá ínsita a intenção de repor o equilíbrio contratual que, mercê da unilateralidade e falta de negociação subjacente, inexiste nas relações entretecidas.

Desenhada a relação entre o princípio da liberdade contratual e as CCG, justificadora do concreto regime normativo deste hodierno modo de contratar, continuemos o caminho proposto.

\section{Caracterização geral da categoria contratual em discussão}

Ponto prévio à análise da temática, objecto deste estudo, será delinear o ponto gravitacional do problema, ou seja, as CCG.

A lei não tem por função apresentar conceitos. Tal tarefa caberá à doutrina. Ainda assim, a regulamentação legal das CCG, introduzida entre nós pelo DL n $446 / 85$, de 25 de Outubro ${ }^{*}$, preocupou-se com esta questão, não numa tentativa de usurpação funcional de tarefas, mas porque a delimitação deste conceito assume sobeja importância relativamente ao âmbito de aplicação do diploma em análise ${ }^{9}$.

A opção do nosso legislador pela fórmula "cláusulas contratuais gerais" não é uniforme na experiência legislativa europeia. De facto, se a $A G B$ Gesetz alemã 10 optou pela expressão "condições negociais gerais" ", a lei francesa " adoptou a fórmula "contratos de adesão". Não

\footnotetext{
Temos, portanto, que a situação de inferioridade do aderente não advém da superioridade económica do pré-disponente, mas da inerente inibição de poder conformar os seus interesses. Para mais desenvolvimentos sobre a génese da inferioridade do aderente, $v$. Sol's A RiBEIRo, Joaquim, o problema do contrato. As cláusulas contratuais gerais e o princípio da liberdade contratual, Coimbra, Almedina, 1997, Cap. II, pp. 177 e ss..

${ }^{8}$ Diploma alterado pelo DL $n^{\circ} 220 / 95$, de 31 de Agosto e pelo DL n 249/99, de 7 de Julho, que de ora em diante será designado de forma abreviada por LCCG e ao qual pertencem todas as disposições legais mencionadas sem especial indicação de proveniência. 'Tanto mais que a Comissão Europeia considerou que Portugal não teria transposto correctamente a Directiva 93/13/CEE precisamente no que a este ponto diz respeito.

Lei aprovada em 9 de Dezembro de 1976.

O nosso legislador preferiu o termo cláusula a condição por esta última possuir um sentido jurídico próprio (vide art. $270^{\circ}$ e ss. do CC). Cfr. Costa, Mário Júlio de Almeida/ CoRDEIRo, António Menezes, Cláusulas contratuais gerais - anotação ao Decreto-
} 
obstante as duas formulações serem utilizadas inđistintamente, os caracteres definidores não são absolutamente coincidentes.

Destarte, constituem traços caracterizadores comuns às duas figuras (contratos de adesão e CCG): a pré-formulação (as cláusulas são elaboradas previamente à celebração do contrato); â unilateralidade (assumindo apenas o predisponente a prerrogativa soberana de fixar o conteúdo contratual) e a rigidez ou imodificabilidade (não assistindo ao aderente a possibilidade de negociação individual do clausulado previamente estabelecido). Acrescem, todavia, às CCG duas características adicionais consubstanciadas, por um lado, na generalidade (as cláusulas pretendem constituir-se como "uma disciplina comum a uma série de contratos" 13) e, por outro lado, na indeterminação (destinando-se a um conjunto não definido de contraentes).

Do exposto resulta claro que "cláusulas contratuais gerais" traduzem um conceito mais restrito que contratos de adesão, na medida em que nem todos os contratos de adesão têm na sua base cláusulas contratuais gerais ${ }^{1415}$.

lei $n^{\circ} 446 / 85$, de 25 de Outubro, Livraria Almedina, Coimbra, 1986, p.18. Vide também Solsa Ribeiro, Joaquim, O problema do contrato..., cit., pp. 130-131

Lei $n^{\circ} 78-23$, de 10 de Janeiro de 1978.

Cfî. Sotsa Ribeiro, Joaquim, Cláusulas contratuais gerais e o paradigma do contrato, Coimbra, 1990, p. 134.

${ }^{14}$ SOCS A RiBEiro desenvolve a distinção em análise, acentuando que as figuras em causa incidem sobre momentos contratuais diferentes de um processo contratual. Assim, se "cláusulas contratuais gerais" pōe em foco a "predisposição das cláusulas para aplicação numa série de contratos", "contrato de adesão" acentua o momento de conclusão do contrato. Cfr. Solsa Ribeiro, Joaquim, Cláulsulas contratuais gerais..., cit., p. 136. No mesmo sentido, cfr. Monteiro, António Pinto, "Contratos de adesão e cláusulas contratuais gerais: problemas e soluções", in: Studia luridica, n 61, 2000, p. 1107.

1. Sobre os efeitos práticos da distinção, viảe comentário de Sotsa RIBEIRo ao litígio objecto da sentença do Tribunal da Cassação italiano, de 22 de Maio de 1986, o qual dizia respeito à intenção de uma empresa cimenteira em construir uma estrada entre o local de fabrico e o de extracção, tendo para o efeito convidado algumas empresas do ramo a endereçarem-lhe propostas de empreitada, as quais deveriam, todavia, obedecer às suas condições pré-formuladas. Cfr. Solsa Ribelro, Joaquim, Cláusulas Contratuais Gerais... cit., nota de rodapé $n^{\circ} 276, p$. 145. Concordamos com SousA RiBEIRo considerando que na factualidade descrita faltariam as notas de generalidade e indeterminação caracterizadoras das CCG, na medida em que a cimenteira não visava utilizar as cláusulas predispostas numa pluralidade de contratos. Em causa estaria um contrato de adesão, mas sem recurso a CCG. 
A nossa lei, logo no art. $1, n^{\circ} 1$, ressalta que o regime instituído por aquele dispositivo legal aplicâ-se a "cláusulas contratuais gerais elaboradas sem prévia negociação individual, que proponentes ou destinatários indeterminados se limitem, respectivamente, a subscrever ou aceitar". Deste preceito ${ }^{16}$ sobressaem, assim, as notas supra referidas, ou seja, a pré-elaboração, a imodificabilidade e a indeterminação.

Até 1999, e tendo em conta o preceituado, a legislação nacional aplicar-se-ia, não só a CCG, mas também a contratos de adesão concluídos através de CCG.

Diferente arrazoado previu a Directiva 93/13/CEE sobre cláusulas abusivas ${ }^{17}$. Tal normativo, elaborado no âmbito de uma profícua política de protecção do consumidor, elege como factor fundamentador da disciplina estabelecida a ausência de negociação, pretendendo estender a sua malha normativa a todos os contratos de adesão, mesmo os que não recorram a cláusulas contratuais gerais. Tal resulta claramente do art. $3^{\circ}$ daquele diploma, o qual manifesta um total silêncio relativamente à ideia de generalidade ou indeterminação ${ }^{18}$.

Em face do exposto, a Directiva apresentava üm âmbito de aplicáção objectivo claramente mais amplo do que o da nossa lei ${ }^{19}$. Apesar do

${ }^{6}$ Que permanece praticamente inalterado face à versão originária de 1985 , apenas tendo sido substituída a expressão de "antemão", por "sem negociação prévia", pelo DL n $220 / 95$. "Publicado no JOCE n ${ }^{\circ} \mathrm{L}$ 95/29, de 21 de Abril de 1993, 29-34, este normativo comunitário surge após um longo período de discussão, marcado por várias alterações ao projecto inicial de 1976. Doravante, este diploma será apenas denominado de Directiva.

: Neste sentido, Sous A RibeIRo refere-se ao surgimento de uma nova categoria negocial consubstanciada no conjunto de cláusulas elaboradas sem prévia negociação com o objectivo de serem integradas sem padecerem de qualquer alteração, mas apenas num único contrato. Cfr. Solsa Ribeiro, Joaquim, O problema do contrato..., cit., p. 602.

"Pelo contrário, no que tange ao âmbito de aplicação subjectivo, o diploma luso é mais abrangente na medida em que estende os seus tentáculos proteccionistas não apenas aos consumidores, mas a qualquer profissional que contrate segundo o modelo descrito no art. $1^{\circ}$. A tímida previsão comunitária é facilmente compreensível se tivermos em conta o circunstancialismo motivador da mesma. Na verdade, inserida no âmbito da política de protecção do consumidor, a Directiva não almejou mais que atender às fragilidades evidenciadas por este sujeito. Consideramos, todavia, de aplaudir a opção do nosso legislador que compreendeu que o ponto nevrálgico deste hodierno modo de contratação não residia nos sujeitos, mas nas suas especificidades subjacentes, concretamente na unilateralidade da formulação das cláusulas. Com efeito, é tão merecedor de tutela, no âmbito da problemática objecto do nosso estudo, um consumidor como um profissional que, confrontado com um clausulado previamente definido, se limita a aderir. 
diploma de $1995^{20}$ ter tido o móbil primordial de transpor aquele diploma comunitário, não esboçou qualquer alteração de fundo nesta questão. De facto, a referência introduzida à ausência de negociação individual resultava já da redacção originária. Em virtude de tal silêncio, a Comissão Europeia, considerando que o seu diploma não estaria correctamente transposto, exige que Portugal altere a regulamentação nacional, o que vem a verificar-se em $1999^{21}$. A partir desta data, mercê da introdução do $\mathrm{n}^{\circ} 2$ no art. $1^{\circ}$ do nosso diploma, e não obstante as críticas que possam ser tecidas relativamente à intervenção legislativa operada ${ }^{22}$, o DL n" $446 / 85$ passou a aplicar-se quer a CCG, quer "às cláusulas inseridas em contratos individualizados, mas cujo conteúdo previamente elaborado o destinatário não pode influenciar".

O quadro traçado anteriormente pretendeu apenas evidenciar as linhas caracterizadoras do fenómeno que ora nos ocupa. Independentemente das diferenças conceptuais que se possam apontar aos conceitos apresentados, no que ao nosso estudo concerne, parece-nos que a intervenção da boa fé no plano de controlo do conteúdo dos contratos é, fundamentalmente, justificada pela unilateralidade e ausência da manifestação da vontade de uma das partes a esse nível, estando esse eixo patente em ambos os diplomas. Obviamente, tal não justifica por si só as especificidades regulamentares previstas. É quando tal unilateralidade assume uma escala generalizada a várias relações contratuais que os principais perigos apontados a este modo de contratação exigem fundamentadamente especiais previsões legais.

E o legislador não ficou alheio à dimensão colectiva das CCG, que se encontra patente em diversos aspectos do regime legal, designadamente no controlo processual abstracto concretizado pela acção inibitó-

${ }^{20}$ Estamo-nos a referir ao DL $\mathrm{n}^{\circ} 220 / 95$, de 31 de Agosto, que alterou a LCCG, conforme supra referido na nota $n^{\circ} 10$.

21 Tal intervenção, levada a cabo pelo DL n ${ }^{\circ} 249 / 99$, de 7 de Julho, não foi, todavia, feliz. A aplicação do regime legal a todos os contratos onde a falta de negociação seja patente revela-se contrária à filosofia fundamentadora de intervenção legislativa neste âmbito excedendo, portanto, o limite do razoável. Repare-se que a nossa lei passou a aplicar-se a todos os contratos nos quais se verifique a ausência de negociação prévia, mesmo que o aderente não seja um consumidor, indo para além dos objectivos da Directiva.

"Sobre as críticas à intervenção legislativa de 1999, vide MonTEIRo, António Pinto, "Contratos de adesão..., cit., pp. 1125 e ss.. 
ria que pode ser desencadeada independentemente da inserção da cláusula em litígio num concreto contrato individual e tendo efeito irradiante para todos os contratos celebrados pelo demandado ${ }^{23}$.

Todavia, na problemática que nos ocupa, a intervenção da boa fé é sobretudo reclamada pela ausência da vontade negocial da parte que se limita a aderir ao conteúdo contratual.

\section{A boa fé como critério de validade das CCG}

A liberdade contratual, paladino das sociedades hodiernas, padece, como supra referido, de fortes limitações quando confrontada com as modernas fórmulas de contratação, concretamente as CCG, exigidas pela realidade económica e social que foi emergindo. Tal limitação não assumiria contornos preocupantes e justificadores de intervenção tuteladora se não viesse acompanhada de abusos e aproveitamentos por parte dos agentes económicos. De facto, a constatação de tais comportamentos menos abnegados, capazes de colocar em causa a confiança do consumidor no mercado e, por outro lado, retirar a própria credibilidade dos agentes económicos, tornou premente a intervenção de um mecanismo que, não se assumindo um remédio para todos os males, pelo menos, elevaria para níveis aceitáveis a transparência do mercado.

Esse mecanismo veio a traduzir-se na boa fé. Na verdade, a boa fé constitui a "espinha dorsal" de todo o regime das CCG.

Sobre a oportunidade e mais-valia deste critério, designadamente quando confrontado com mecanismos similares, e sobre a sua verdadeira função no âmbito que afloramos, ocupar-nos-emos nas páginas seguintes.

\section{O sistema de controlo de conteúdo das CCG: o método ineren- te ao catálogo de proibições}

Antes de mais desenvolvimentos, convém delinear os traços gerais do sistema de controlo de conteúdo das CCG patente na lei nacional. Tal sistema articula uma cláusula geral que se consubstancia na boa fé ${ }^{24}$,

\footnotetext{
Vide art. $25^{\circ}$ da LCCG.

${ }^{2} \mathrm{~V}$. art $15^{\circ} \mathrm{da} \mathrm{LCCG}$.
} 
com um amplo leque de cláusulas consideradas proibidas, por se revelarem abusivas ${ }^{25}$.

Tal leque, plasmado em quatro preceitos legais ${ }^{26}$, é orientado por duas bissectrizes fundamentais. Por um lado, os sujeitos que entretecem a relação contratual e, por outro lado, a "forma de actuação da proibiça $o^{\prime \prime}$ "

Assim, quanto à primeira bissectriz, o legislador prevê duas listas de proibições para as relações contratuais estabelecidas entre empresá$\operatorname{rios}^{28}$, elencando posteriormente mais dois preceitos para as relações com consumidores ${ }^{29}$. Trata-se de uma distinção singular no panorama legal dos restantes países da U.E. que se mostra em coerência com o âmbito de aplicação subjectivo adoptado. Por outro lado, denota também a compreensão de que o nível de protecção reclamado nas relações entre empresários ou entidades equiparáveis é inferior, rectius, específico, ao que é exigível nas relações com consumidores ${ }^{30}$.

Relativamente à segunda bissectriz, distinguem-se cláusulas absolutamente proibidas que, pelo seu "desvalor abstractamente pressuposto pelo legislador" "si são imediatamente proibidas sem que o julgador estabeleça qualquer diálogo com o concreto esquema negocial em que se inserem e cláusulas relativamente proibidas, as quais reclamam do

${ }^{25}$ O legislador italiano declinou o emprego da expressão abusiva, preferindo o termo "vessatorio". Sobre as razões justificativas de tal preferência, v. Trovatore, Gianfranco, "La definizione atipica delle "clausole abusive" tra controllo giudiziale e trattativa individuale", in: Rev. Trim. di Dir. e Proc. Civ., Anno LI, n 4 (Dicembre 1997), pp. 969 e ss..

${ }^{26}$ Vide arts. $18^{\circ}, 19^{\circ}, 21^{\circ}$ e $22^{\circ}$ da LCCG.

${ }^{27}$ Expressão colhida nos escritos de Almeno de SÁ. Cfr. Almeno de SÁ, Cláusulas Contratuais Gerais e Directiva sobre Cláusulas Abusivas, $2^{\text {a }}$ edição, Almedina, p. 76.

${ }^{28}$ Recorde-se que o campo de aplicação subjectivo da nossa lei ultrapassa os limites propostos pela Directiva Comunitária, abarcando no seu âmbito não apenas os consumidores mas qualquer entidade empresarial que se veja confrontada com este especial modo de contratação. Sobre esta opção legislativa vide supra nota 23.

${ }^{29} \mathrm{Na}$ verdade, o primeiro conjunto, e por força do artigo $20^{\circ}$, aplica-se de igual modo às relações em que uma das partes seja consumidor, acrescendo uma proteção adicional. ${ }^{30}$ Sobre as diferenças de tratamento que as relações entre empresários mereceram por parte do legislador português, v. CosTA, Mário Júlio de Almeida/CordeIro, António Menezes, Cláusulas contratuais gerais..., cit., pp. 37-38.

:Tal como nos refere Almevo de SÁ. Cfr. Almeno dE SÁ, Cláusulas Contratuais Gerais..., cit., p. 76. 
juiz decidendi uma intrínseca valoração mediatizada pelo designado "quadro negocial padronizado". Concretizando, se relativamente às cláusulas absolutamente proibidas o mero preenchimento da previsão legal conduz ao seu afastamento do clausulado, no que tange às cláusulas relativamente proibidas, elas exigem um concreto juízo valorativo que deverá convocar, não a pura exigência de justiça do caso concreto, mas o modelo contratual em que se insere a cláusula ${ }^{32}$.

As previsões legais supra referidas não consubstanciam mais do que concretizações da cláusula geral da boa fé - o filtro de validade à luz do qual todas as cláusulas têm de encontrar justificação. Desta forma, não é suficiente a não inclusão de uma disposição contratual no quadro das proibições constantes nos arts. $18^{\circ}, 19^{\circ}, 21^{\circ}$ e $22^{\circ}$, para que a mesma tenha passado com distinção o teste de validade legalmente exigido. De facto, tal disposição terá ainda que ser aprovada pelos critérios redensificadores da boa fé ${ }^{33}$.

\section{Boa fé, bons costumes e ordem pública}

Traçado que está, em termos gerais, o sistema de fiscalização de conteúdo das CCG, resta-nos desbravar o caminho proposto inicialmente, analisando agora, de forma mais atenta, as concretizações normativas do princípio geral da boa fé. A primeira questão que se nos coloca é avaliar das valências desta cláusula geral quando confrontada com outros arrimos similares, designadamente, os bons costumes e a ordem pública.

\footnotetext{
${ }^{32}$ Assim, se a cláusula, cujo carácter abusivo é invocado, disser respeito ao estabelecimento de obrigações perpétuas num concreto contrato de locação financeira celebrado com recurso a CCG, tal cláusula é imediatamente afastada por preencher o art. $18^{\circ}$, al. j). Porém, se em causa estiver a previsão de prazos excessivos - vide art $22^{\circ}$, al. a) para a vigência do contrato, então já o julgador terá de levar a cabo um juízo valorativo, tendente ao preenchimento do conceito "excessivos", convocando não o concreto contrato em análise, mas o modelo contratual geralmente estabelecido na locação financeira.

"É esta última sindicância que, inexplicavelmente, nem sempre é levada a cabo pelos tribunais nacionais. $\mathrm{Na}$ verdade, no âmbito do percurso metodonomológico que percorrem, limitam-se a analisar as várias listas elencadas na regulamentação legal e, na eventualidade da cláusula objecto de controlo não se inserir nas mesmas, dão por terminada a sua caminhada, quando faltava ainda, last but not least, a aferição da sua validade à luz da cláusula geral da boa fé.
} 
Face ao carácter situacional da boa fé, chamada a operar em circunstâncias particularizadas, parecia impossível a sua aplicação a relações caracterizadas pela generalidade e indeterminação.

$\mathrm{Na}$ verdade, o princípio da boa fé deixa de intervir como regulador da conduta das partes no âmbito da execução de uma concreta relação contratual, para passar a actuar, a priori, na previsão do conteúdo de cláusulas, independentemente da sua inserção em contratos individualizados, instituindo, desta forma, limites ao poder de conformação unilateral do predisponente, cuja inobservância redundará na invalidade das mesmas.

Não constituindo a boa fé, nas palavras de Sousa RiBEIRo ${ }^{34}$, "uma "panaceia universal», sempre disponível para colmatar os défices de fundamentação das soluções desejadas", urge analisar a prestabilidade funcional de tal princípio nos termos prescritos anteriormente.

Várias foram as vozes que se insurgiram contra a previsão legislativa da boa fé no domínio das CCG. Neste sentido, OLIVEIRA ASCENSÃO ${ }^{35}$ advoga que, tendo a boa fé objectiva ínsita a instituição de regras de conduta condenatórias de "tipos de exercício" que a violem, tal nada tem a ver com os problemas levantados por aquela figura, concluindo mesmo que "a referência à boa fé é (...) meramente retórica. Não tem função nenhuma".

Mas o papel chamado a desempenhar pela boa fé na matéria que afloramos é, precisamente, controlar o exercício do poder unilateral de conformação do conteúdo de um contrato que conduz, as mais das vezes, a cláusulas injustificadamente desfavoráveis para uma das partes.

É certo que, em concreto, é avaliado o conteúdo contratual predisposto, mas a validade do mesmo só é questionável porque para a sua conformação não contribuíram duas vontades plenamente livres.

Por outro lado, o ponto rector desta problemática reside também na exigência que deve ser imposta a todo aquele que, assumindo um papel regulamentador de uma relação contratual, muitas vezes a despeito das previsões legislativas, não pode deixar de atender, tal como faria o legislador, aos interesses da contraparte.

${ }^{34}$ Vide Sousa Ribeiro, Joaquim, O problema do contrato..., cit, , p. 551.

${ }^{35}$ Cfr. AsCEnsão, José de Oliveira, "Cláusulas Contratuais Gerais, Cláusulas Abusivas e Boa Fé", in: Revista da Ordem dos Advogados, ano 60, II, Lisboa (Abril 2000), pp. $587-588$. 
Com efeito, tendo presente a vocação generalizadora das CCG, similar à das normas jurídicas, deve exigir-se do predisponente o mesmo compromisso legislativo subjacente à actuação da entidade legiferante, ou seja, o atendimento dos interesses de ambos os sujeitos ${ }^{36}$.

Vejamos melhor a pertinência da boa fé neste contexto ${ }^{37}$, tendo em conta a análise de outros pressupostos dogmáticos.

No que tange aos bons costumes, e atendendo à linha de pensamento traçada por MENEZES CORDEIRO ${ }^{38}$, para além do cariz originariamente associado à moral, esta cláusula geral pode constituir um limite à liberdade contratual mas não almeja prescrever "o teor do comportamento a assumir", em concreto, pelo predisponente no momento de estabelecimento do conteúdo contratual.

Por outro lado, os boni morus não representam tanto um juízo de censura a cláusulas de sentido inverso ao prescrito pelo direito dispositivo, mas mais, inculcam a ideia de contrariedade a princípios e valores fundamentais do ordenamento jurídico.

Já no que concerne à ordem pública, torna-se difícil afirmar a superioridade das valências da boa fé face àquela. De facto, a ordem pública afirma-se como o reflexo de um conjunto de princípios imanentes ao próprio ordenamento jurídico, impondo limites ao exercício da autonomia privada dos particulares quando esta signifique um afastamento ou mesmo uma derrogação daqueles. É, assim, "uma cláusula de salvaguarda, de preservação, no essencial da coerência normativa, visando impedir que a descentralização de competência reguladora abra as portas a rupturas e contradições dentro do sistema" "39.

Nestes termos, parecia constituírem as CCG um campo por excelência de actuação da ordem pública. Não obstante, não foi essa a opção

\footnotetext{
${ }^{36}$ Refira-se, neste contexto, a sentença do BGH de 4.11.1964 onde se lê que "Quem põe em vigor condições gerais dos contratos reivindica para si em exclusivo, no que respeita à conformação do conteúdo, a liberdade contratual. Está por isso obrigado, segundo a boa fé, já na redacção das condições, a considerar devidamente os interesses dos seus futuros parceiros contratuais. Se fizer valer apenas os seus próprios interesses, abusa da liberdade contratual". Cfr. Sousa Ribeiro, Joaquim, O problema do contrato..., cit., p. 553.

${ }^{37}$ Que concordamos ter, tal como nos refere SOL'SA RIBEIRO, um papel diferente da sua "função originária”. Cfr. Sousa RuberRo, Joaquim, O problema do contrato..., cit., p. 542.

${ }^{3}$ Cfr. Cordeiro, António Menezes, Boa fé no Direito Civil, Almedina, 1983, pp. 1197 e ss..

${ }^{3}$ Cfr. Sousa Riberro, Joaquim, O problema do contrato..., cit., p. 527.
} 
legislativa que, indubitavelmente influenciada pela previsão alemã ${ }^{\circ 0}$, acaba por consagrar a cláusula geral da boa fé.

Tal preferência não coloca, ainda assim, em causa a prestabilidade funcional desta cláusula no domínio das CCG. De facto, tal conceito tem assumido novas valências ao longo do tempo redensificando-se e ganhando novos contornos operativos.

Por outro lado, a função que é convocada a desempenhar neste âmbito também não se afasta radicalmente do conceito de boa fé objectiva, se tivermos em conta que a conduta do predisponente é também alvo de apreciação crítica face àquele princípio.

Efectivamente, e como referido anteriormente, o que se pretende é que aquele que se arroga do poder de conformação unilateral do conteúdo dos contratos a celebrar no futuro, atenda, segundo a boa fé, aos interesses dos seus eventuais parceiros contratuais que, face às especificidades deste modo de contratação, não puderam fazer actuar plenamente a sua autodeterminação ${ }^{4}$.

Deste modo, a referida cláusula gerai vai controlar o "exercicio disfuncional da autonomia privada" 42 , operando no sentido de evitar que, não só sejam inatendidos os interesses do aderente, mas principalmente que as concretas estipulações contratuais, afastando-se do direito dispositivo ${ }^{43}$, redundem num desequilibrio injustificado de direitos e obrigações a favor do predisponente.

\footnotetext{
${ }^{+0}$ Cfr. $\$ 9$ da Lei alemã.

"Acompanhamos assim Sousa Ribeiro, para quem "A fundamentação da operatividade da boa fé, neste campo, aproxima-se, (...) de certo modo, da que sustenta a sua aplicação nos casos de intervenção de alguém na esfera de outrem, assumindo uma posição que the permite assenhorear-se do controlo de um eventual dano para este: quem, por espontânea iniciativa própria, tem nas suas mãos o destino de um interesse alheio deve comportar-se por forma a não lesar esse interesse. Cfr. Sousa Ribeiro, Joaquim, O problema do contrato..., p. 555. Nestes termos compreende-se que, se a boa fé não desempenha o papel que originariamente lhe foi traçado, também não se afasta disfuncionalmente das virtualidades que lhe são apontadas.

Cfr. Sol'sa Ribeiro, Joaquim, cit., p. 566.

$\because$ O direito dispositivo, sem pretender constituir-se como ius cogens, assume o papel de padrão do equilíbrio pretendido numa relação contratual. Nestes termos, o seu afastamento é capaz de despoletar uma justificada sindicância do conteúdo contratual. ALMENO DE Sá fala a este respeito da função-modelo do direito dispositivo. Cfr. AlMENo dE SÁ, Cláusulas Contratuais Gerais..., cit., p.72.
} 
A boa fé concorre, assim, para o estabelecimento de limites à liberdade de conformação do conteúdo contratual sempre que ela ataque de forma irrazoável os interesses da parte que, mercê da impossibilidade prática de intervenção, se limitou a aceitar o clausulado predisposto.

É com este significado que a boa fé é também acolhida pela Directiva Comunitária. Todavia, como veremos no ponto seguinte, as concretizações ao princípio fixadas neste diploma e na legislação nacional não coincidem.

\section{Critérios operativos da boa fé}

\section{Análise do artigo $16^{\circ}$ do DL $n^{\circ} 446 / 85$}

Discutida a opção legislativa pela boa fé no diploma regulador das $\mathrm{CCG}$, cumpre agora analisar os critérios operativos fornecidos pelo legislador para apoiar a entidade decidendi na aplicação daquela cláusula ao caso concreto.

$\mathrm{Na}$ verdade, a boa fé só logra adquirir consistência prática quando aplicada a uma situação concreta, tendo o julgador de operar um juízo mediador entre as exigências daquela cláusula geral e o caso em análise. Todavia, tal não pode significar uma margem de actuação completamente livre, devendo ser fornecidas ao juiz concretizações susceptíveis de justificar a concreta decisão e permitir um controlo jurisdicional desta. Essas concretizações foram apontadas no art. $16^{\circ}$ do DL n ${ }^{\circ} 446 / 85$.

$\mathrm{Da}$ análise deste preceito resulta constituírem critérios concretizadores da boa fé, o princípio da confiança (alínea a)) por um lado, e os objectivos negociais visados pelas partes (alínea b)), por outro. Assim enunciados, parece que os mesmos reflectem apenas os arrimos dogmáticos comummente convocados por aquela cláusula geral, não inovando nem, principalmente, atendendo à específica função exercida pela boa fé neste âmbito ${ }^{44}$.

Efectivamente, foi propósito confessado do legislador ${ }^{45}$ consagrar tais arrimos em moldes vagos capazes de se adaptarem a novos contor-

\footnotetext{
* Neste sentido SOUSA RIBERRO refere que "Nada de novo, ou de particularmente útil em matéria de auxílio às decisões judiciais sobre a validade das ccg traz, nessa medida, o disposto no art.16․" Cfr. Sousa RibeIRo, Joaquim, o problema do contrato..., cit., p. 569. ${ }^{15}$ Cfr. Costa, Mário Júlio de Almeida/ Cordeiro, António Menezes, Cláusulas contratuais gerais..., cit., pp. 40-41.
} 
nos económicos e sociais, denotando, desta forma, a clara compreensão de que em causa estava um fenómeno contratual não transitório, mas que poderia adquirir novas roupagens no evoluir normal das relações comerciais.

Como refere Almeno de SÁ 46 , "na lei portuguesa é exclusivamente convocado o princípio da boa fé, sem que seja indicada, de forma expressa, uma «medida» ou contrapólo aferidor que marque o particular horizonte de sentido pelo qual o juiz, no quadro genérico daquele princípio, deva orientar a sua intervenção correctora".

Contudo, apesar da lei não lograr fornecer imediatamente a fórmula de qualificação de uma cláusula como abusiva, por contrária à boa fé, aquela não pode deixar de estar implícita nas especificidades deste concreto modo de contratar, justificadoras da própria intervenção legislativa. Tendo nós concluído anteriormente que a boa fé é convocada neste domínio para estabelecer limites ao poder de conformação unilateral do conteúdo contratual do predisponente, sempre que ela ataque de forma irrazoável os direitos e obrigações da contraparte, a medida de controlo do julgador só poderá ser o equilíbrio de interesses plasmado no conteúdo contratual, condenando as situações de desfavor injustificado para o aderente.

É tendo em conta esta bitola que se deve procurar concretizar o alcance prático dos critérios consagrados.

Relativamente ao princípio da confiança plasmado na alínea a) do art. $16^{\circ}$, OLIVEIRA ASCENSÃO ${ }^{47}$ considera-o um critério de "grande vacuidade", afirmando que pode "o destinatário não depositar a menor confiança no predisponente e todavia celebrar o contrato, por não ter na prática outro remédio".

A predita posição, além de se mostrar de todo indiferente ao campo normativo que afloramos, esquece que, em qualquer relação contratual - mesmo sem recurso a CCG -, é normal as partes celebrarem o contrato, não obstante o sentimento de desconfiança relativamente ao outro contraente, elevando apenas o cuidado prescritivo relativamente às estipulações contratuais.

\footnotetext{
${ }^{4}$ Cfr. Almeno de SÁ, Cláusulas Contratuais Gerais..., cit., p. 71.

"Cfr. AsCensÃo, José de Oliveira, "Cláusulas Contratuais Gerais..., cit., p. 590.
} 
O que está aqui em causa não pode ser a confiança assente na pessoa do predisponente, mas no conteúdo contratual prescrito por este e que o aderente não pôde influenciar.

E esta afirmação ganha maior relevo se atentarmos nos factores susceptíveis de gerar a confiança digna de tutela. Desde logo, quanto "ao sentido global das cláusulas contratuais em causa", não poderá estar em foco "o pressuposto (...) de que o aderente tomou conhecimento preciso do alcance do conjunto das ccg e firmou, com base nelas, uma sólida confiança num determinado sentido vinculativo do contrato" ${ }^{48}$. Contra tal pressuposto basta recordar que a prática corrente reflecte a total desmotivação pela leitura do clausulado, que normalmente se apresenta como uma longa e complexa lista de preceitos de conteúdo jurídico.

$\mathrm{Na}$ verdade, o que importa avaliar é se as circunstâncias que basearam a decisão de contratar do aderente fundaram uma confiança digna de tutela contrária ao conteúdo contratual. Pois, se o contraente raramente desperdiça energias na leitura do contrato, não estará alheio às mensagens fornecidas, maxime, pela pubilicidade, que lihe poderão gerar expectativas relativamente a um resultado que determinada cláusula contraria. Tal ideia é corroborada pela referência adicional, na alínea a) do art $16^{\circ}$, ao "processo de formação do contrato singular celebrado".

Recuperando o referido anteriormente, a análise das concretizações indicadas pelo legislador não pode ser desligada das especificidades deste modo de contratar. E é tendo em conta esse parâmetro que o princípio da confiança deve ser atendido neste âmbito.

No que à al. b) diz respeito, ela assenta no fim contratual visado pelas partes ${ }^{49}$. Neste caso, o que está em causa é aferir da compatibilidade entre o conteúdo contratual e o objectivo negocial almejado pelos contraentes, considerando-se uma cláusula contrária à boa fé sempre que a finalidade ambicionada seja invertida. Para exemplificar esta situação, basta pensarmos num contrato de seguro cujo conteúdo con-

Cfr. Solsa Ribeiro, Joaquim, O problema do contrato ... cit., p. 577.

${ }^{\prime 9}$ Almeida COSTA e MENEzes CORDEIRo traduzem esta vertente concretizadora de boa fé na "necessidade de ponderar a materialidade da disciplina jurídica". Cfr CostA, Mário Júlio de Almeida/ CORderro, António Menezes, Cláusulas contratuais gerais... cit., p. 41 . 
tratual conduza a uma restrição ou mesmo isenção da responsabilidade da seguradora que torne inócuo o contrato concretamente celebrado.

Entra novamente aqui em linha de conta o poder regulamentador do predisponente que unilateralmente fixa cláusulas contratuais negligenciando os objectivos visados, a despeito das exigências de boa fé, na celebração de um concreto tipo contratual ${ }^{50}$.

Do que fica dito realça-se que, não obstante o carácter vago das concretizações da boa fé plasmadas no art. $16^{\circ}$ da LCCG, o seu efectivo alcance só pode alcançar-se atendendo, por um lado, às especificidades deste modo de contratar e, por outro, ao juízo valorativo em causa, que se consubstancia em determinar se as cláusulas predispostas traduzem um desequilíbrio contratual injustificado para uma das partes.

Reforçando esta linha de pensamento basta convocarmos para esta análise a panóplia de cláusulas previstas nos arts.18 $, 19^{\circ}, 21^{\circ}$ e $22^{\circ}$, as quais espelham precisamente a preocupação de evitar a previsão de vantagens desmesuradas para o predisponente, em detrimento do aderente, sem razão atendível ${ }^{5 !}$. Constituindo estas tipifícaçôes legâis da cláusula geral de boa fé, as mesmás reflectem indubitavelmente o sentido que o legislador quis imprimir àquele princípio. E é tendo em conta este sentido que devemos compreender os critérios operativos presentes no art $16^{\circ}$.

Acresce que, como nos diz Sousa RiberRo ${ }^{52}$, a referência aos "valores fundamentais de direito" no supra mencionado art.16 , diz respeito à "equivalência contratual que deve presidir à modelação das ccg" o que nos remete novamente para o eixo de valoração a ter em conta neste âmbito, ou seja, a ponderação de interesses entre as partes, sem desequilíbrios injustificados.

Concluindo, compreendemos e aceitamos que o princípio da confiança e os objectivos negociais visados pelas partes não logrem ofere-

\footnotetext{
${ }^{50}$ Concordando inteiramente com SOtSA RibeIRo, a al. b), apesar das valências práticas que possui, não pode funcionar autonomamente, mas em correlação com os critérios operativos anunciados anteriormente, sob pena de escaparem ao filtro de validade da boa fé todas as cláusulas que, não colocando em causa o fim negocial pretendido, traduzam um desequilibrio injustificado para o aderente. Cfr. SOLSA RIBEIRO, Joaquim, $O$ problema do contrato..., cit., p. 579.

${ }^{51}$ Neste sentido atente-se nas alíneas $g$ ), h) e i) do art.19 e nas alíneas b), g), i), j) e n) do art. $22^{\circ}$.

"Cfr. Sous a Riberro, Joaquim, O problema do contrato..., cit., p. 583.
} 
cer o critério imediato de aferição do carácter abusivo de uma cláusula contratual gerai. Na verdade, o que importa avaliar é se uma cláusula redunda na prática num desequilíbrio prestacional em detrimento do aderente, sem razão justificativa.

Questionar-se-á então quando existirá aquele desequilíbrio ou qual o padrão para aferirmos o equilíbrio ideal? Dir-se-á que esse padrão reside no direito dispositivo.

E quando confrontados com a ausência de direito dispositivo por omissão de prescrição legislativa em determinada matéria? O critério aferidor do equilíbrio ideal não terá de ser os objectivos prosseguidos pelas partes e a confiança suscitada? Parece-nos assim que os critérios operativos da boa fé consagrados pelo legislador não são despiciendos mas antes concorrem para a concretização correcta daquela cláusula geral.

\section{$\mathrm{O}$ art. $3^{\circ}$ da Directiva sobre cláusulas abusivas}

Focando agora atenções no dipioma comunitário, ele prescreve no seu art. $3^{\circ}$ que uma "cláusula contratual (...) é considerada abusiva quando, a despeito da exigência de boa fé, der origem a um desequilíbrio significativo em detrimento do consumidor, entre os direitos e obrigações das partes decorrentes do contrato".

Numa apreciação apressada do articulado, parece lograr a Directiva maior clarividência que a nossa lei, uma vez que apresenta imediatamente como padrão de controlo de validade das CCG o desequilíbrio significativo entre os direitos e obrigações das partes.

Todavia, uma análise mais atenta do preceituado este levanta questões interpretativas não despiciendas, cuja correcta solução torna-se imperativa se tivermos em conta a vocação uniformizadora do diploma ${ }^{53}$.

Na verdade, o critério apontado pela directiva - "desequilíbrio significativo em detrimento do consumidor" - não visa indicar qual o equilíbrio ideal para se determinar o desequilíbrio inaceitável.

\footnotetext{
${ }^{53}$ Não pretendemos abordar aqui os problemas levantados relativamente à inserção em determinados ordenamentos jurídicos, maxime, de raiz anglo-saxónica, do conceito de boa fé. Sobre esta temática vide Telbner, Gunther, "Legal Irritants: Good faith in British Law or How Unifying Law Ends Up in New Divergences", in: The Modern Law Review, vol.61, n 1, January 1998, pp.11-32.
} 
Por outro lado, afasta-se da necessidade de ponderação dos interesses contratưais de ambas as partes. Atende somente à desproporção negocial estabelecida contratualmente a desfavor do aderente ${ }^{54}$ sem convocar para a análise a existência de factores justificativos do desequilíbrio. De facto, não basta que se verifique um desequilíbrio entre os direitos e obrigações das partes, é também necessário que esse desequilíbrio, mais que significativo, se mostre irrazoável ou inadequado ${ }^{55 / 56}$.

E esta ausência de manifestação prescritiva relativamente ao atendimento da existência ou não de razões justificativas para o conteúdo contratual, assume contornos preocupantes quando o próprio Tribunal de Justiça das Comunidades ${ }^{57}$, assenta a sua análise apenas na óptica do consumidor, negligenciando os interesses do predisponente.

Nestes termos, atente-se no Acórdão Oceano Grupo Editorial e Salvat Editores SA C. Rocío Murciano Quintero e outros ${ }^{58}$, no qual se discutia o carácter abusivo de uma cláusula que, contendo um pacto de aforamento, conferia competência exclusiva ao tribunal do foro da sede do predisponente. Em causa estavam contratos de compra e venda a prestações de enciclopédias celebrados entre grupos editoriais e vários sujeitos domiciliados em Espanha, os quais, não tendo pago as importâncias devidas nas datas de vencimento estabelecidas, foram demandados a fim daquelas obterem o pagamento das importâncias em falta. O Tribunal concluiu que a supra referida cláusula fazia "pesar sobre o consumidor a obrigação de se submeter à competência exclusiva de um tribunal que por estar afastado do seu domicílio, pode dificultar a sua comparência em juizo" "59, integrando-se, desta forma, no art. $1^{\circ}$, al. q), do anexo da Directiva. Em nenhuma das considerações tecidas, foi feita uma apreciação relativa à existência de razões justificativas daquela previsão contratual. Na verdade, o acórdão não nos

\footnotetext{
${ }^{54}$ Que na Directiva se circunscreve a um consumidor. Cfr. supra nota 21.

"Termo acolhido na Lei alemã no $\S 9$ e que nos parece preferível a "significativo".

${ }^{56}$ Neste sentido, ALMEIDA CosTA, considera "preferível a solução da nossa lei, uma vez que os interesses a ponderar podem assumir várias expressões. Cfr. CosTA, Mário Júlio de Almeida, Direito das Obrigações, $8^{\text {a }}$ edição, Coimbra, Almedina, 2000, nota 3. p. 24. 5 Órgão, de ora em diante, designado abreviadamente por Tribunal ou TJC.

${ }^{ \pm}$Ac. $n^{\circ} 240 / 98$, de 27 de Junho de 2000 , que pode ser consultado no endereço electrónico http://curia.eu.int/pt/content/juris/index.htm, consultado pela última vez em 23 de Fevereiro de 2006.

${ }^{59}$ Cfr. parágrafo 22 do referido Acórdão.
} 
fornece dados suficientes, mas deveria ter sido questionado, por exemplo, o local da celebração do contrato, pois na eventualidade das partes demandadas se terem deslocado à sede das editoras para adquirir as referidas enciclopédias, mal se compreende agora que não possam efectuar a mesma deslocação para o tribunal, tanto mais que foram elas próprias que deram origem à demanda ao não pagar as prestações devidas. Se o local da celebração do contrato coincidir com o foro competente poderá não se vislumbrar um ataque tão forte aos direitos dos aderentes.

Aparte desta análise, que repetimos não poder ganhar maior consistência face à omissão de circunstâncias factuais, gostaríamos ainda de chamar à colação a cláusula congénere da nossa lei, nomeadamente, a al. g), do art. $19^{\circ}$, a qual prescreve serem relativamente proibidas as estipulações que "estabeleçam um foro competente que envolva graves inconvenientes para uma das partes, sem que os interesses da outra o justifiquem". Daqui se infere precisamente que não basta uma previsão desfavorável para uma das partes, sendo necessário aferir se o desequilíbrio provocado é ou não irrazoável ${ }^{\text {to. }}$.

Não podemos, todavia, tecer uma análise ao normativo comunitário desligada, quer da sua génese histórica, quer do longo processo formativo que a sua publicação envolveu ${ }^{6 !}$.

$\mathrm{Na}$ verdade, se, por um lado, a Directiva pretendeu construir uma solução de compromisso entre as várias legislações nacionais já existentes sobre a matéria, designadamente a alemã e a francesa, por outro, tentou não concretizar demasiado os seus preceitos, por forma a facilitar a sua transposição e adaptação aos ordenamentos internos dos Estados-Membros.

\footnotetext{
${ }^{6}$ Neste sentido vide Acórdão da Relação de Lisboa, de 8 de Maio de 2003, Col. de Jurisprudência, n 167, Ano XXVIII, Tomo III, 2003. Nesta decisão foi considerada válida uma cláusula de imposição do tribunal competente, cuja nulidade havia sido requerida pelo réu, por este não ter demonstrado "que os interesses da Autora não possam justificar, só por si, a convenção aprazada".

${ }^{6 !} \mathrm{Na}$ verdade, o primeiro ante-projecto desta Directiva data de 1976 e, apenas em 1992 foi adoptada pela Comissão a proposta final que, nas palavras de MÁrio TENREIRo, "was more than a reformulation of the original text: it was practically a new text". Cfr. MÁrio TeNREIRo, "The Community Directive on Lnfair Terms and National Legal Systems: The Principle of Good Faith and Remedies for Unfair Terms", in: European Review of Private Law, n. 3, 1995, p. 273.
} 
Dos quatro critérios enunciados na proposta inicial ${ }^{62}$, apenas restou o preceituado no art. $3^{\circ}$ da Directiva, o quâl ñão pơde interpretar-se autonomamente, sem qualquer articulação com as exigências de boa fé também contempladas no dispositivo comunitário. De facto, ao contrário do que já foi sustentado ${ }^{63}$, os dois critérios apontados (boa fé, por um lado, e desequilíbrio significativo, por outro), não podem operar isoladamente, sendo que, em concreto, um desequilíbrio significativo é susceptível de violar as exigências impostas pela boa fé se for considerado inadequado.

Esta parece-nos ser a melhor interpretação conforme os trabalhos preparatórios, os objectivos da Comissão e o próprio entendimento do papel que a boa fé assume neste âmbito.

Acresce que, não obstante o entendimento do Acórdão Océano, o TJC, tendo sido novamente convocado em 2004 para se pronunciar sobre o carácter abusivo de uma cláusula, refere-se claramente, no parágrafo 18 do acórdão elaborado, a um "desequilíbrio significativo e injustificado" "64.

Em face do exposto, as dúvidas supra levantadas perdem pertinência diluindo-se na correcta compreensão do preceito em análise.

${ }^{62}$ Cfr. Mário Tenreiro, "The Community Directive..." , cit., p. 274.

"Na Conferência organizada pela Comissão em Bruxelas, a 3.7.1999, com o objectivo de analisar a aplicação da Directiva cinco anos após a sua publicação, foi defendido por um participante que uma cláusula seria abusiva se resultasse num desequilíbrio significativo ou se fosse contrária às exigências da boa fé. Cfr. European Commission, "The unfair terms directive, five years on: evaluation and future perspectives, Luxembourg: Office for Official Publications of the European Communities, 2000, p. 132.

${ }^{4} \mathrm{Cfr}$. Acórdão $n^{\circ} \mathrm{C}-237 / 02$, de 1 de Abril de 2004, que pode ser consultado no endereço electrónico http://curia.eu.int/pt/content/juris/index.htm, consultado em 20 de Dezembro de 2005 . 


\section{CONCLUSÃO}

O trilho traçado inicialmente visava a análise dos critérios concretizadores da boa fé no âmbito das CCG.

Para o efeito, mostrou-se necessário delinear os contornos deste fenómeno, relacionando-o com o princípio da liberdade contratual. Percebemos que, apesar deste hodierno modo de contratação desafiar os contornos definidores daquele princípio, tal não significava a sua total erosão. Em causa está apenas a convocação de certos arrimos para que o postulado fundamental da autonomia privada se concretize. A intervenção legislativa levada a efeito pelo $D_{L} n^{\circ} 446 / 85$, não tem ínsita outra intenção que não essa.

A temática do precedente estudo reclamava, por outro lado, a caracterização da categoria contratual em discussão. Com efeito, os traços definidores das CCG justificaram os especiais cuidados de regulamentação que esta figura mereceu, não só no plano nacional, como europeu. Concluímos então que, não obstante todas as suas notas caracterizadoras fundamentarem o regime prescrito legalimente, no concreto âmbito sobre o qual nos debruçamos, eram a unilateralidade e ausência de negociação imediatamente justificadoras da intervenção da boa fé no controlo do conteúdo dos contratos celebrados pelas CCG.

E partimos desta premissa para a análise do papel da boa fé como critério de validade deste modo de contratar. De facto, perante as especificidades das CCG, a função desenvolvida por aquela cláusula geral assume um novo perfil. Norteada pelo objectivo de garantir a realização em concreto da liberdade contratual, a boa fé intervém como reguladora do exercício do poder de modelação unilateral do conteúdo das estipulações contratuais por parte do predisponente.

Constatámos que pela utilização generalizada das CCG, aquele que fica investido da mesma capacidade prescritiva do legislador, deve ter ínsitas as preocupações deste, mormente, um correcto equilíbrio dos direitos e obrigações das partes contratuais.

A boa fé apresenta-se neste cenário com um papel, não de integradora da vontade de uma das partes, mas como substitutiva de uma vontade que não almeja mais que aceitar (ou não) as estipulações previamente predispostas. 
$E$, nestes termos, aquele princípio assume maiores valências que critérios próximos como os bons costumes.

A correcta compreensão da funcionalidade operativa da boa fé mostrou-se fundamental na análise dos seus critérios concretizadores, designadamente, o princípio da confiança e os objectivos negociais visados pelas partes. Na verdade, a consagração sui generis destes operadores, face ao direito comparado, exigiu o estudo do seu alcance operativo que apenas logrou ganhar consistência quando articulado com aquela função, definida nos moldes supra mencionados.

Tais critérios constituem, desta forma, meritórios arrimos do julgador na avaliação do factor que, em última instância, dita o carácter abusivo de uma cláusula, scilicet, o desequilíbrio contratual injustificado para uma das partes.

Terminámos o presente estudo com uma abordagem ao normativo europeu sobre a mesma matéria, tendo-se concluído que também aqui a compreensão do preceituado só se almeja quando articulada com a intenção legislativa inerente ao mesmo. Efectivamente, o sentitido literal do art. $3^{\circ}$ da Directiva não pode deixar de ter subjacente que, neste âmbito, o que importa averiguar é a existência ou não de uma desproporção injustificada dos direitos e obrigações das partes.

$\mathrm{O}$ atendimento apenas do ponto de vista de uma das partes, maxime do aderente, em vez de concorrer para a realização plena do princípio da liberdade contratual, redundaria na sua aniquilação. $O$ contrato deixaria de espelhar a vontade unilateral do predisponente, para passar a reflectir a vontade dos seus parceiros contratuais legalmente imposta.

Conclui-se então que, o fio de prumo no âmbito das CCG, concretamente dos critérios operativos da boa fé nesta matéria, reside no correcto equilíbrio entre direitos e obrigações das partes que qualquer estipulação contratual deve traduzir, sendo este o sentido que as prescrições legislativas lograram consagrar. 


\section{BIBLIOGRAFIA}

ALMEIDA, António, "As cláusulas contratuais gerais e o postulado da liberdade contratual", in: Lusíada: Revista de Ciência e Cultura, Série de Direito, Coimbra, n² 2, 1998, pp. 283-312.

Almeno DE SÁ, Cláusulas Contratuais Gerais e a Directiva sobre Cláusulas Abusivas, $2^{a}$ edição, Coimbra, Almedina, 2001.

AsCensão, José de Oliveira, "Cláusulas Contratuais Gerais, Cláusulas Abusivas e Boa Fé", in: Revista da Ordem dos Advogados, ano 60, II, Lisboa, Abril 2000, pp. 573-595.

CALAIS-AUlOY, Jean, "Les clauses abusives en droit français", in: Revue européenne de droit de la consomation, Paris, $\mathrm{n}^{\circ} 4,1988$, pp. 287-293.

CANARIS, Claus-Wilhelm, "A liberdade e a justiça contratual na «sociedade de direito privado»", in: Contratos: actualidade e evolução, Porto, 1991, pp. 58-66.

Castrillo Santos, Juan, "Autonomía y heterononimía de la voluntad en los contratos, in: Anuario de derecho civil, Mádrid, tomo 2, $\mathrm{n}^{\circ}$ 2, Abril-Junio1949, pp. 565-605.

CORdEIRo, António Menezes, "A boa fé nos finais do século XX", in: Revista da Ordem dos Advogados, Lisboa, ano 56, n 3, Dezembro 1996, pp. 887-912

- Tratado de Direito Civil Português - I Parte Geral, Tomo I, $2^{2}$ Edição, Livraria Almedina, 2000.

- Da boa fé no Direito Civil, Coimbra, Almedina, 1983.

CosTA, Mário Júlio de Almeida, "Intervenções fulcrais da boa fé nos contratos", in: Estudos do Direito do Consumidor, Coimbra, n ${ }^{\circ} 2$, 2000, pp. 357-368.

- Síntese do regime jurídico vigente das cláusulas contratuais gerais, $2^{a}$ Edição revista e actualizada, Universidade Católica Editora, Lisboa 1999.

- Direito das Obrigações, 8 edição, Coimbra, Almedina, 2000.

Costa, Mário Júlio de Almeida/ Cordeiro, António Menezes, Cláusulas contratuais gerais - anotaçâo ao Decreto-lei $n^{\circ} 446 / 85$, de 25 de Outubro, Livraria Almedina, Coimbra, 1986.

DrAY, Guilherme Machado, "Breves notas sobre o ideal de justiça contratual e a tutela do contraente débil", in: Estudos de homena- 
gem ao Prof. Doutor Inocêncio Galvão Telles/ Estudos organizados pelos Professores Doutores António Menezes Cordeiro, Luís Menezes Leitão e Januário da Costa Gomes, Vol. I, Coimbra, Almedina, 2002, pp. 75-105.

EuROPEAN COMMISSION, "The unfair terms directive, five years on: evaluation and future perspectives, Luxembourg: Office for Official Publications of the European Communities, 2000, p. 132.

Frota, Mário, "A lei das condições gerais dos contratos", in: Revista Portuguesa de Direito do Consumo, Coimbra, $n^{\circ} 4$, Outubro de 1995, pp. 311-318.

- "As condições gerais dos contratos em direito português", in: Revista Portuguesa de Direito do Consumo, Coimbra, $\mathrm{n}^{\circ} 12$, Dezembro1997, pp. 37-50.

GOMES, Luiz Roldão de Freitas, "As cláusulas abusivas e o poder de integração do juiz", in: Separata de Studia Iuridica, 73, 2003.

Goyens, Monique, "Clauses Abusives: position commune du Conseil du 29 juin 1992", in: Revue europeenne de droit de la consommation, 1992, pp. 154-155.

Guersi, Carlos Alberto, "La buena fe: limite al derecho subjetivo del contratante predisponente", in: Revista del notariado, ano 90, $\mathrm{n}^{\circ}$ 809, Abril/Junio 1987, pp. 443-451.

MonteIro, António Pinto, "La Directive «clauses abusives», 5 ans après - A transposição para a Ordem Juridica interna da Directiva 93/13/CEE", in: Boletim da Faculdade de Direito, Coimbra, Vol. 75, 1999 , pp. 523-536.

- "Contratos de adesão: o regime jurídico das cláusulas contratuais gerais instituído pelo Decreto-lei $n^{\circ} 446 / 85$, de 25 de Outubro", in: Revista da Ordem dos Advogados, ano 46, Lisboa, 1986, pp. 733-769.

- "Contratos de adesão e cláusulas contratuais gerais: problemas e soluções", in: Boletim da Faculdade de Direito, Studia Iuridica, $\mathrm{n}^{\circ} 61$, 2000, pp. 1103-1131.

MonTEIRo, Jorge Sinde/ Horster, Heinrich, "A lei alemã para a regulamentação do regime das condições gerais dos contratos", in: Revista de Direito e Economia, n 5, 1979, pp. 417-441.

Nascimento, Luís António Noronha, "As cláusulas contratuais gerais na Jurisprudência do supremo Tribunal de Justiça", in: Estudos de Direito do Consumo, Coimbra, n 5, 2003, pp. 99-122. 
Oliverra, Nuno Manuel Pinto, "A lei das cláusulas contratuais gerais e a Directiva $n^{\circ}$ 93/13/CEE de 5 de Abril de 1993", in: Scientia Iuridica, Tomo 54, n 303, Julho/Setembro de 2005, pp. 527-558.

SMORTo, Guido, "Il principio di buona fede nella disciplina delle clausole abusive", in: Revista critica del dirritto privado, Napoli, ano 17, n 1-2, Giugno 1999, pp. 101-157.

Sousa RiBEIRo, Joaquim, Cláusulas contratuais gerais e o paradigma do contrato, Coimbra, 1990.

- O problema do contrato. As cláusulas contratuais gerais e o princípio da liberdade contratual, Coimbra, Almedina, 1997.

- Responsabilidade e garantia em cláusulas contratuais gerais ( $D L n^{\circ}$ 446/85, de 25 de Outubro), Coimbra, 1992.

- "Direito dos contratos e regulação do mercado", in: Revista Brasileira de Direito Comparado, Rio de Janeiro, n²2, 2002, pp. 203-223.

TenreIro, Mário, "The Community Directive on Unfair Terms and National Legal Systems: The Principle of Good Faith and Remedies for Unfair Terms", in: European Review of Private Law, n. 3, 1995, p. 273.

Teubner, Gunther, "Legal Irritants: Good faith in British Law or How Unifying Law Ends Up in New Divergences", in: The Modern Law Review, vol.61, n 1, January 1998, pp. 11-32. 


\section{SIGLAS E ABREVIATURAS}

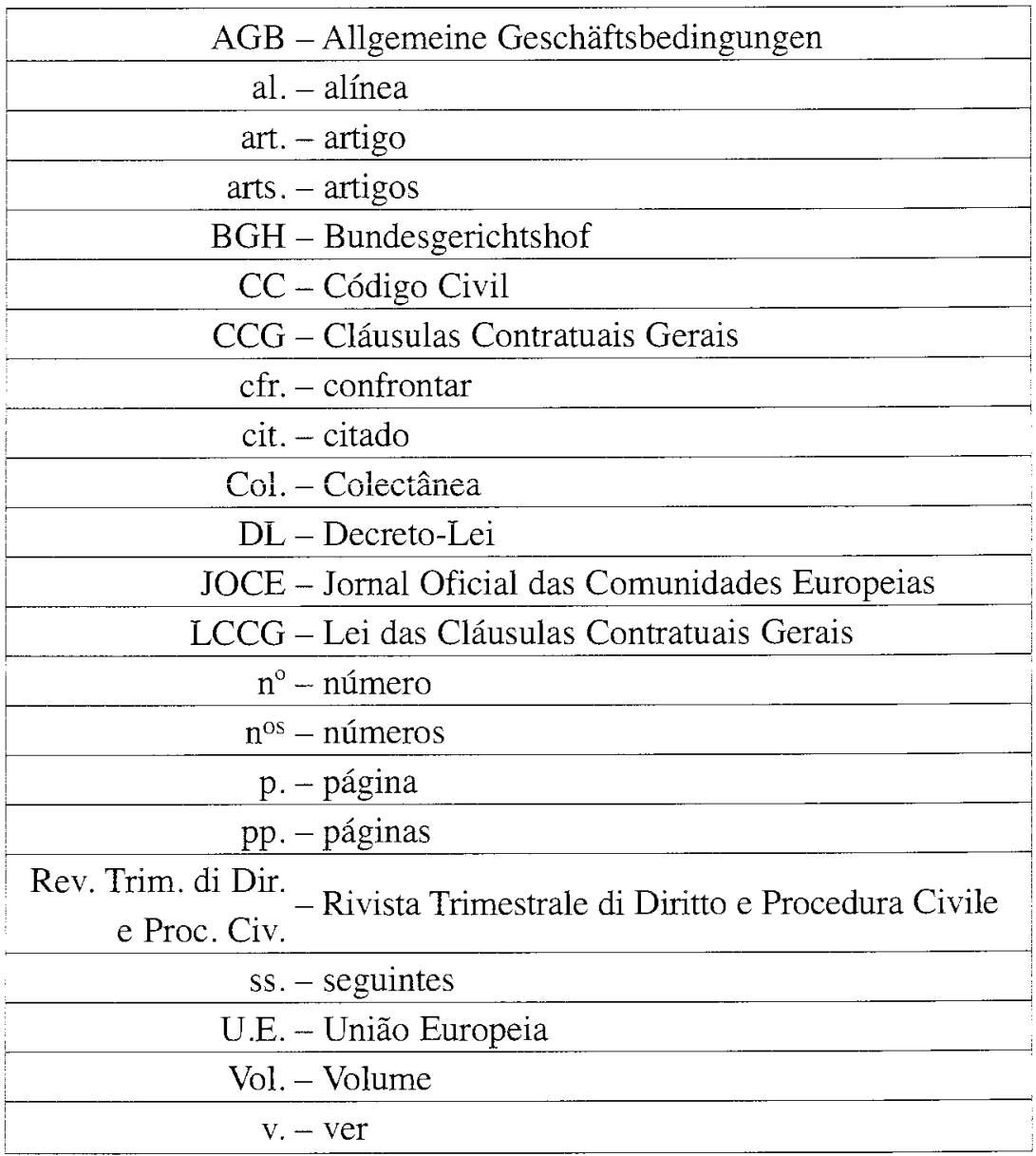

